WENJUN LUO, Ph.D. ${ }^{1}$

E-mail: Iwj06051979@163.com

LONG CHENG, M.Sc. ${ }^{1}$

E-mail: 1580171291@qq.com

LIHONG TONG, Ph.D. ${ }^{1}$

E-mail: Ihtong@ecjtu.edu.cn

WENNIAN YU, Ph.D. ${ }^{2}$

(Corresponding author)

E-mail: wennian.yu@queensu.ca

CHRIS K. MECHEFSKE, Ph.D. ${ }^{2}$

E-mail: chris.mechefske@queensu.ca

${ }^{1}$ East China Jiaotong University

Economic and Technological Development District

808 Shuanggang East Street, Nanchang, Jiangxi,

330013, China

2 Queen's University, 130 Stuart Street,

Kingston, Ontario, K7L 3N6, Canada
Traffic and Environment (Ecology)

Preliminary Communication

Submitted: 5 Sep. 2017

Accepted: 30 Jan. 2018

\title{
PREDICTION AND ANALYSIS OF STRUCTURAL NOISE FROM A U-BEAM USING THE FE-SEA HYBRID METHOD
}

\begin{abstract}
With urban rail transit noise becoming an increasing ly serious issue, accurate and quick analysis of the low to medium frequency spectral characteristics of this noise has become important. Based on the FE-SEA (Finite Element - Statistical Energy Analysis) hybrid method, a vibration prediction model of a U-beam was established using a frequency-dividing strategy. The frequency domain and spatial characteristics of the vibration and structural noise of the U-beam within the $1.25-500 \mathrm{~Hz}$ frequency range, when subjected to vertical wheel-rail interaction forces, were analyzed. Compared with other methods described in the literature, the proposed FE-SEA hybrid method improves the calculation efficiency while ensuring better accuracy for a wide frequency range of structural noise and vibration. It was found that the excitation frequencies of the wheel-rail force dominate the spectra of the vibration and structural noise of the U-beam. Therefore, the frequency band containing the excitation frequencies should be the target for noise and vibration reduction when implementing strategies. The results show that the bottom plate contributes the most to the sound pressure level at all prediction points, and therefore should be the focus for noise and vibration reduction.
\end{abstract}

\section{KEY WORDS}

U-beam; local vibration; structural noise; sound pressure contribution; Finite Element-Statistical Energy Analysis hybrid method;

\section{INTRODUCTION}

Urban rail transit bridge structural noise is a relatively low-frequency noise. It can easily penetrate walls and other obstacles, which will negatively affect human attention, response time, and language recognition ability [1]. Due to its low structural height, lightweight properties, shape, and noise isolation properties (the web plates can serve as obstructions to the transmission of noise from the wheel-rail), the U-beam rail carriage construction shape is widely used in urban rail transit vehicles. However, there is still insufficient research on local vibration and structural noise radiation from this type of structure. In addition, the problem of bridge structural noise involves a wide range of research objects, and the interactions among these objects are complex. Therefore, it is difficult to analyze the noise field of the typical bridge structure by analytical methods. Schulte-Werning et al. [2] and Alten and Flesch [3] presented measurement evidence confirming that large peaks in bridge acceleration and the associated bridge-borne noise usually occur at frequencies around $70 \mathrm{~Hz}$. Thompson [4] provided some examples of measured noise level spectra from steel railway bridges. Significant peaks at frequencies around $40 \mathrm{~Hz}$ could be observed in the spectra, regardless of the train speed. Nevertheless, the cause of the low-frequency vibration and noise was not identified in the subsequent high-frequency-oriented statistical energy analysis. Bewes and Thompson [5] established a computational model to simulate the noise radiation from a railway bridge structure using the Statistical Energy Analysis (SEA) method. Compared with the experimental results, the proposed model can yield a comparatively accurate result in the $40-100 \mathrm{~Hz}$ frequency range. Li et al. [6] studied the vibration and noise of a railway box girder using a three-dimensional boundary element method and experimental verification. It was found that using the plate elements to 
analyze the dynamics of the railway structures can better reflect their local vibration characteristics. It was also noted that the noise from the railway structure has the widest radiation region and slowest attenuation rate at $63 \mathrm{~Hz}$. Han et al. [7] analyzed the effects of plate thickness and stiffening on the noise of U-beam construction using the modal superposition method. They pointed out that the bottom plates of the U-beam construction have a larger influence on the structure noise in the far field than its web plates, and increasing the thickness of the bottom plate is more effective in reducing the noise than increasing the thickness of the web plates. Li et al. [8] researched the acoustic radiation characteristics of the structural noise from a $32 \mathrm{~m}$ long simply-supported U-shaped girder bridge on a high-speed railway. Their results showed that the simply-supported trench-shaped beam has a small torsional rigidity, and its structure-borne noise is significantly affected by its local vibration. Li and $\mathrm{Wu}$ [9] carried out a numerical simulation and field measurement of low frequency structural noise of a concrete bridge. The analysis results indicated that the proposed numerical method can better predict the low-frequency structural noise radiated from the practical concrete railway bridge under the excitation of the vehicles. Song et al. [10] predicted the low frequency noise of a U-beam of rail transit concrete based on the 2.5-dimensional infinite element method. Compared with calculation results using the 3-dimensional boundary element method, the proposed method can quickly predict the structural noise of bridge without losing much accuracy.

Currently, numerical methods for the noise analysis of urban rail transit include finite element method (FE), boundary element method (BEM), statistical energy method (SEA), and infinite element method. The FE method is suitable for the structural vibration response analysis in the middle and low frequency bands. However, for complex dynamic systems, the computational efficiency is not satisfactory. The computation time of BEM increases rapidly with the increase of the degree of freedom considered. Besides, it will be time-consuming for high frequency analysis. SEA has poor prediction accuracy for low frequency analysis, possibly due to insufficient number of bending modes considered. Therefore, how to accurately and efficiently predict the vibration and noise transmission characteristics of the U-beam to allow effective investigation of vibration and noise reduction is still a problem worthy of further study.

In this paper, a vehicle-rail coupling model is established using the SIMPACK software to obtain the vertical wheel-rail interaction force. According to the modal density of the U-beam plates, FE and FE-SEA bridge models are established respectively for plates having lower modal density (lower than 5) and plates having higher modal density (higher than 5 ) by using the VA
One software for the analysis of different frequency bands (frequency-dividing strategy). The local vibration and the structural noise characteristics of the U-beam section under the action of the vertical wheel-rail interaction force are analyzed in the 1/3 octave frequency domain. On this basis, the contribution of the sound pressure, the vibration energy, and U-beam vibration power loss are calculated and compared with the numerical results and measured results provided in the literature.

\section{PREDICTIVE MODEL AND RELATED THEORY}

\subsection{The basic theory of hybrid method}

Langley and Cordioli [11] defined the boundary in their FE-SEA model with known physical properties as the deterministic boundary, whereas the boundary with unknown physical properties was defined as the random boundary. In addition, according to the boundary condition, the displacement field at the boundary was classified as the direct field and the reverberation field. For the FE-SEA model, the elastic wave is reflected at the coupling boundary between the FE subsystem and the SEA subsystem, and the FE subsystem is subjected to the additional force of the reverberation field. Thus, the displacement response of the deterministic FE subsystem is:

$\mathbf{D}_{t} \mathbf{q}=\mathbf{f}_{e}+\sum_{k=1}^{N} \mathbf{f}_{r}^{k}$

where $\mathbf{D}_{t}$ is the overall stiffness matrix of the subsystem; $\mathbf{q}$ is the generalized coordinate of the response for the subsystem; $\mathbf{f}_{e}$ is the external excitation; $\mathbf{f}_{r}^{k}$ is the force sensed by the $k$-th random subsystem in the reverberation field.

Based on the reciprocal relationship of the diffusion field, the following equation can be obtained [8]:

$\mathrm{E}\left[\mathbf{f}_{r}^{k} \mathbf{f}_{r}^{(k) \mathrm{H}}\right]=\frac{4 E_{k}}{w \pi n_{k}} \operatorname{Im}\left[\mathbf{D}_{d}^{k}\right]$

where $\mathrm{E}[\cdot]$ is the population mean function; $\mathbf{H}$ is the matrix operation notation representing the conjugate transpose of a matrix; $n_{k}$ is the modal density of the $k$-th random subsystem; $w$ is the circular frequency; $E_{k}$ is the energy of the $k$-th random subsystem; $\operatorname{Im}[\cdot]$ is the imaginary part of a complex variable; $\mathbf{D}_{d}^{k}$ is the dynamic stiffness matrix for the direct field.

The expression of the cross-spectral matrix can be obtained based on Equations 1 and 2 [11]:

$\mathbf{S}_{q q}=\mathrm{E}\left[q q^{\mathrm{H}}\right]=\mathbf{D}_{t}^{-1}\left[\mathbf{S}_{f f}+\sum_{k=1}^{N}\left(\frac{4 E_{k}}{w n_{k} \pi}\right) \operatorname{Im}\left[\mathbf{D}_{d}^{k}\right]\right] \mathbf{D}_{t}^{-\mathrm{H}}$

where $\mathbf{S}_{q q}$ is the displacement cross-spectrum matrix; $\mathbf{S}_{f f}$ is the excitation cross-spectrum matrix. 
For random subsystems, the energy response is:

$w\left(n_{j}+n_{d_{j}}\right) E_{j}+\sum_{k=1}^{N} w \eta_{j, k} n_{j}\left(\frac{E_{j}}{n_{j}}+\frac{E_{k}}{n_{k}}\right)=P_{i n, j}^{e x t}+P_{i n, j}$

where $n_{j}$ is the internal loss factor of the $j$-th stochastic subsystem; $n_{d, j}$ is the coupling loss factor for the mixture consisting of the $d$-th deterministic subsystem and the $j$-th stochastic subsystem; $n_{j, k}$ is the effective coupling loss factor between the $j$-th and $k$-th stochas tic subsystem; and $P_{i n, j}^{e x t}$ is the input power of the $j$-th subsystem due to the external excitation, and $P_{i n, j}$ is the input power due to other factors.

After obtaining the energy of the random subsystem through Equation 4 and the displacement response of the deterministic subsystem through Equation 3, the physical quantities (such as the speed and acceleration) of the subsystem can be acquired. Based on this, the sound pressure at any point can be obtained by the acoustic radiation theory.

\subsection{Acoustic radiation of a bridge structure}

The U-beam structure can be considered as a system consisting of multiple rectangular plates with the same size (subsystems), whose width and length are $a$ and $b$, respectively. Then, the radiated sound power can be expressed as [12]:

$W_{i}=\rho_{a} c_{a} \sigma_{i} S_{i}\left(\bar{v}_{i}^{2}\right)$

where $\rho_{a}$ is the air density $\left(\mathrm{kg} / \mathrm{m}^{3}\right), c_{a}$ is the noise velocity in the air $(\mathrm{m} / \mathrm{s}), \sigma_{i}$ is the radiation efficiency of the $i$-th subsystem, $S_{i}$ is the superficial area of the $i$-th subsystem $\left(\mathrm{m} / \mathrm{s}^{2}\right)$, and $\bar{v}_{i}^{2}$ is the mean square value of the velocity $\left((\mathrm{m} / \mathrm{s})^{2}\right)$.

Suppose the vertical distance from point $Q$ to the center of a rectangular plate is $r$, when $r \leq a / \pi$, the noise source emits a plane wave whose magnitude does not attenuate with its traveling distance. The mean square value of the sound pressure at point $\mathrm{Q}$ radiated from the $i$-th subsystem is:

$\left(\bar{p}_{i}^{2}\right)_{M}=\frac{\pi \rho_{a} c_{a} W_{i}}{4 a b}$

When $a / \pi<r<b / \pi$, the noise source can be approximated as an infinite line noise source, then:

$\left(\bar{p}_{i}^{2}\right)_{M}=\frac{\pi \rho_{a} c_{a} W_{i}}{4 b r}$

When $r \geq b / \pi$, the noise source can be simplified as a point noise source, then:

$\left(\bar{p}_{i}^{2}\right)_{M}=\frac{\pi \rho_{a} c_{a} W_{i}}{4 \pi r^{2}}$

The linear superposition principle can be used to obtain the total sound pressure of the U-beam at point $\mathrm{Q}$ based on the individual sound pressure of each plate $\left(p_{i}\right)$ at that point.
To analyze the contribution of each plate vibration on the total sound pressure of a certain point, the sound pressure contribution coefficient $D_{c}$ is introduced [7]:

$D_{c}=\operatorname{Re}\left(\frac{\mathbf{P}_{c} \mathbf{P}^{*}}{|\mathbf{P}|^{2}}\right)$

where $\operatorname{Re}(\cdot)$ is the real part of a complex number, $\mathbf{P}$ is the total sound pressure at a certain point, $\mathbf{P}^{*}$ is conjugate with $\mathbf{P}$, and $\mathbf{P}_{c}$ is the sound pressure radiated from each subsystem at a certain point.

\subsection{Simulation analysis process}

The simulation process is shown in Figure 1. First, through the SIMPACK rail coupling model, the time domain vertical wheel force signal is calculated. Then, after FFT analysis and 1/3 octave conversion in MAT$\mathrm{LAB}$, the equivalent wheel-rail interaction forces corresponding to the center frequencies of the 1/3 octave bands can be obtained. After that, according to the modal density of U-beam plates, FE (if modal density is lower than 5) and SEA (if modal density is higher than 5) U-beam models are built for analysis in the low and high frequency ranges, respectively. The vibration response of the U-beam is obtained by applying the equivalent wheel-rail interaction forces in the 1/3 octave frequency domain on the mid-point of the bridge in a most unfavorable loading way according to the track and the vehicle sizes. Based on this, the structural noise and vibration energy of the U-beam are predicted and analyzed.

\section{MODEL AND VALIDATION}

\subsection{Vehicle-rail coupling model}

A vehicle-rail coupling model is established using the SIMPACK software for a passenger carriage of A-type subway train, as shown in Figure 2. The total mass of the carriage (car body) is $48,835 \mathrm{~kg}$. The mass of each bogie is $3,970 \mathrm{~kg}$. The mass of each wheel is $1,654 \mathrm{~kg}$. The vertical stiffness (rigidity) and damping of the first suspension are $1.26 \times 10^{6} \mathrm{~N} / \mathrm{m}$ and $10,626 \mathrm{Ns} / \mathrm{m}$, respectively. The vertical stiffness and damping of the second suspension are $4.9 \times 10^{5}$ $\mathrm{N} / \mathrm{m}$ and $20,590 \mathrm{Ns} / \mathrm{m}$, respectively. The German high disturbance roughness spectrum is adopted when considering the track irregularity [13-15], which assumes the wavelength of irregularity as $0.25 \mathrm{~m}$ to 30 $\mathrm{m}$. The train speed is about $70 \mathrm{~km} / \mathrm{h}$. By defining the geometric relationship of the wheel-rail contact, the hinge of the subsystem, and the setting of the force element and other parameters, the time-domain vertical wheel-rail interaction force can be obtained. The bogie is hinged with six degrees of freedom, and the body is hinged with five degrees of freedom. The rail type is 


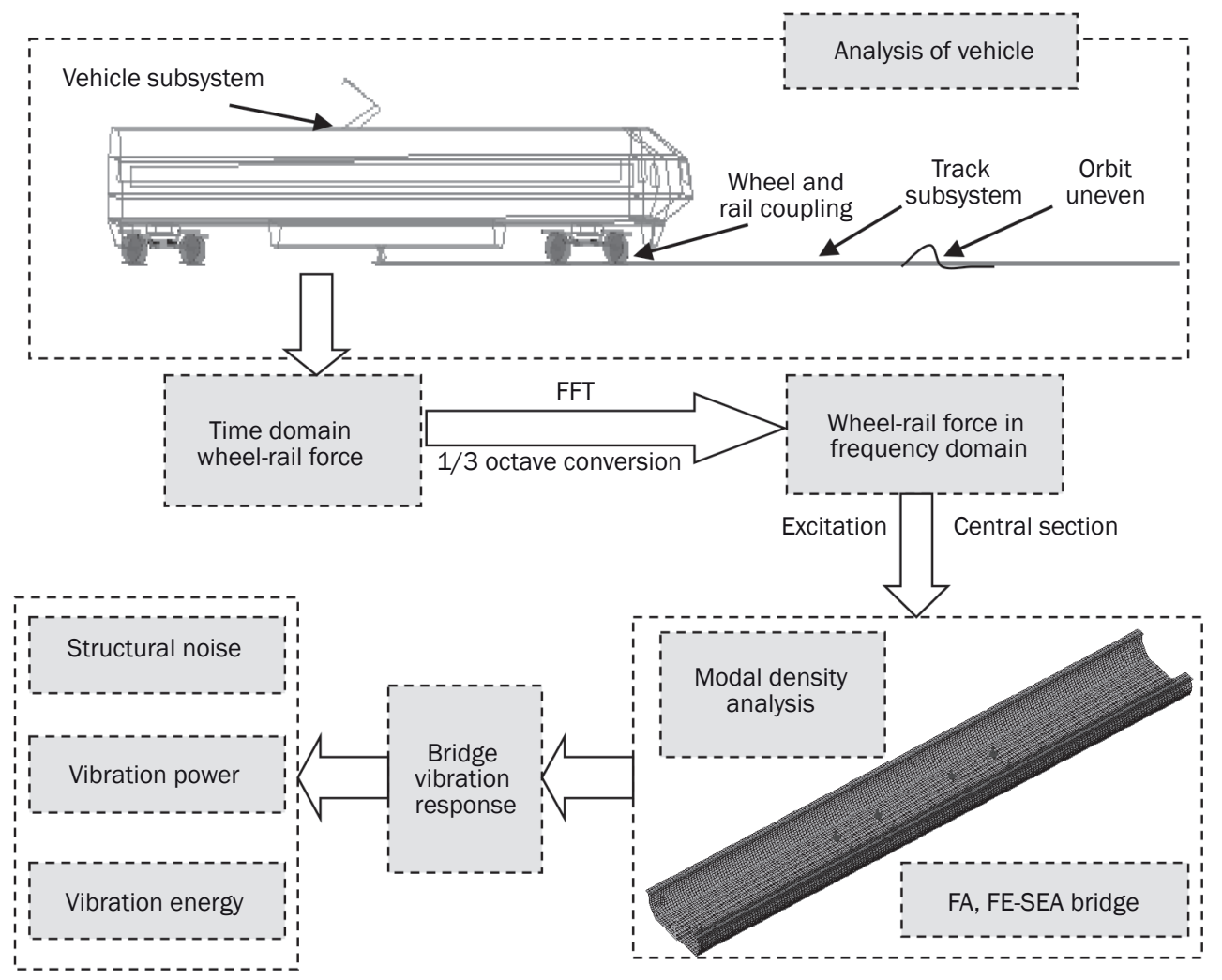

Figure 1 - Simulation flowchart of the vibration and noise analysis for a U-beam structure

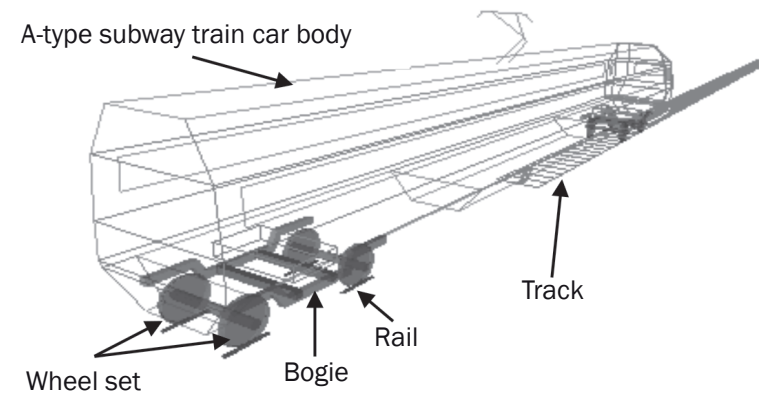

Figure 2 - Vehicle-rail coupling model

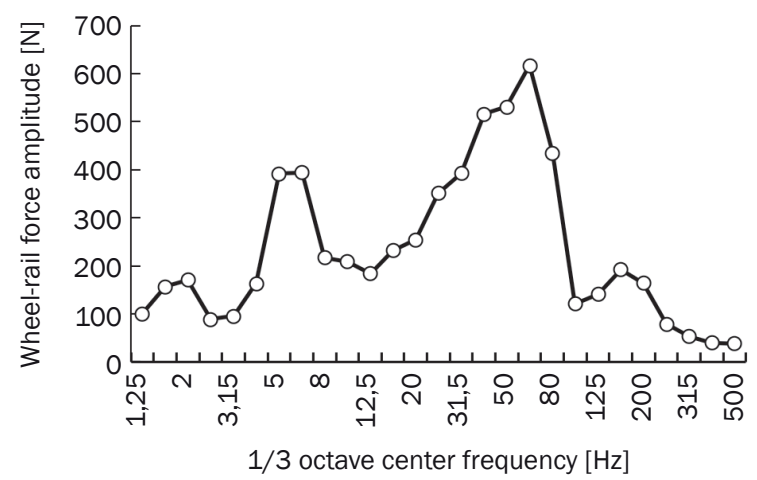

Figure 3 - Amplitude spectrum of wheel-rail interaction force
UIC60, and the wheel-rail contact is single-constraint. In order to accurately describe the wheel-rail contact relationship, the track, wheel reference, wheel profile reference, rail profile reference, wheel contact, and rail contact are introduced in the wheel-rail modeling to describe the relative movement of each rigid body of the rail and vehicle. After FFT analysis and 1/3 octave conversion, the effective wheel-rail interaction forces corresponding the center frequencies of the 1/3 octave bands can be obtained. As shown in Figure 3, the maximum-amplitude frequency of the wheel-rail interaction force is $63 \mathrm{~Hz}$. There are also peaks at about 5 $\mathrm{Hz}$ to $6 \mathrm{~Hz}$ and about $160 \mathrm{~Hz}$.

\subsection{U-beam model}

A $30 \mathrm{~m}$ single-line simply supported U-beam of a rail transit project is established by the VA-one software. The cross section of the U-beam is shown in Figure 4. The thicknesses of the left and right wing plates of the U-beam are $0.425 \mathrm{~m}$ and $0.31 \mathrm{~m}$, respectively. The height of the beam is $1.8 \mathrm{~m}$. The thicknesses of the web plates and the bottom plate are all 0.28 $\mathrm{m}$. The width of the bottom plate is about $3.6 \mathrm{~m}$. The radii of the left and right web plates differ slightly. The material of the U-beam is C55 concrete, with elastic modulus of $34.5 \mathrm{GPa}$, shear modulus of $14.38 \mathrm{GPa}$, density of $2650 \mathrm{~kg} / \mathrm{m}^{3}$, Poisson's ratio of 0.2 , and loss factor of 0.04 . The simply supported boundary condition is simulated using a point constraint [16]. 


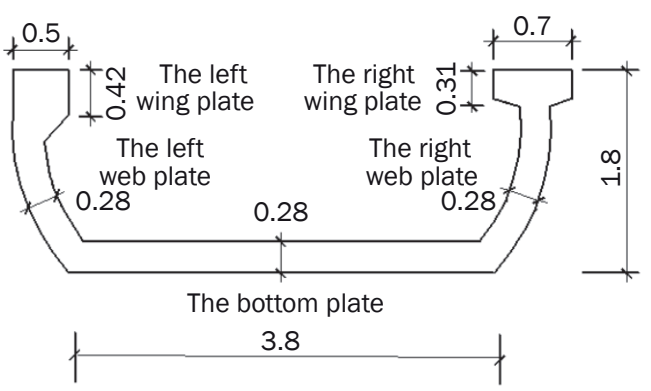

Figure 4 - Cross section of the U-beam [m]

For an A-type subway car, there are 2 bogies. Given the actual geometries of the car body and the bridge, the most unfavorable loading diagram is shown in Figure 5. There are simultaneously 2 car bodies on the $30 \mathrm{~m}$ long bridge, while each has only one bogie on the track (Point A or D), whose distance to the corresponding end of the bridge is $10.2 \mathrm{~m}$. The distance between the two wheel sets of a bogie (AB or CD) is $2.5 \mathrm{~m}$, and the minimum wheel distance between adjacent car bodies is $4.6 \mathrm{~m}(\mathrm{BC})$.

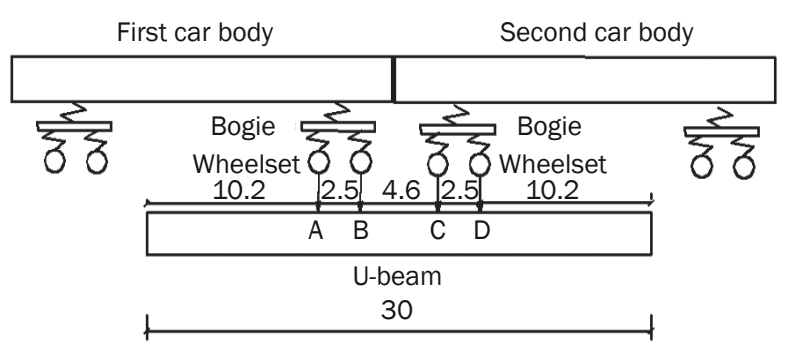

Figure 5 - The most unfavorable loading diagram [m]

The vibration and acoustic radiation of the U-beam are analyzed in the frequency range of $1.25 \mathrm{~Hz}$ to 500 $\mathrm{Hz}$. The plate and shell elements are used when building the model with the consideration of calculation accuracy and computational efficiency. The relationship between the bending mode density and the center frequency of each $1 / 3$ octave band of the beam under the wheel-rail interaction force is shown in Figure 6 and Table 1. The modeling strategy, where different types of models (FE and SEA models) are built on different frequency bands (frequency-dividing strategy) for different plates, is carried out according to whether the bending mode density under the wide band excitation is higher than 5 or not [17-18].

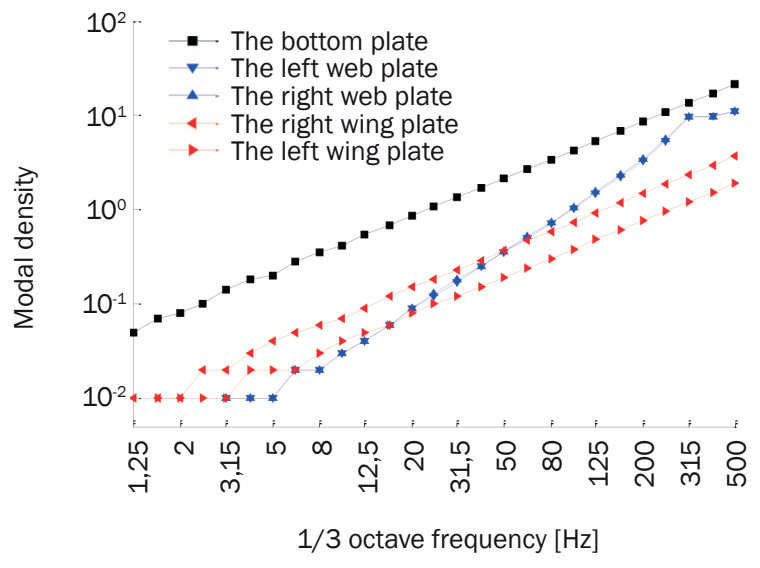

Figure 6 - Relationship between the bending mode density and frequency of each section of U-beam

In the low frequency range of $1.25 \mathrm{~Hz}$ to $125 \mathrm{~Hz}$, the U-beam plate does not meet the requirement for establishing a SEA model. Therefore, a whole FE structure is established in this frequency band, and the size of the elements is $0.15 \mathrm{~m}$, which satisfies the precision requirement. In the $125 \mathrm{~Hz}$ to $250 \mathrm{~Hz}$ frequency range, the bending mode density of the bottom plate is higher than 5, so the SEA subsystem is established. The web plates and the wing plates are still FE subsystems. In the $250 \mathrm{~Hz}$ to $500 \mathrm{~Hz}$ frequency range, only the wing plates modal density is lower than 5 , so it is built as FE subsystem. The bottom and web plates are still SEA subsystems. The overall model of the U-beam is shown in Figure 7. Each plate of the $U$ beam is classified into different subsystems in different frequency bands as shown in Table 2.

Table 2 - Classification of subsystems

\begin{tabular}{||c|c|l||}
\hline $\begin{array}{c}\text { Frequency } \\
\text { band }[\mathrm{Hz}]\end{array}$ & $\begin{array}{c}\text { Subsystem } \\
\text { type }\end{array}$ & \multicolumn{1}{|c|}{ Plate name } \\
\hline \hline \multirow{2}{*}{$1.25-125$} & FE & $\begin{array}{l}\text { The bottom plate, the web } \\
\text { plates, the wing plates }\end{array}$ \\
\cline { 2 - 3 } 125-250 & SEA & $\backslash$ \\
\cline { 2 - 3 } & FE & $\begin{array}{l}\text { The web plates, the wing } \\
\text { plates }\end{array}$ \\
\hline \multirow{2}{*}{$250-500$} & FEA & The bottom plate \\
\cline { 2 - 3 } & SEA & $\begin{array}{l}\text { The wing plates } \\
\text { plates }\end{array}$ \\
\hline
\end{tabular}

Table 1 - Bending mode density

\begin{tabular}{||l|c|c|c|c|c|c|c||}
\hline \multicolumn{1}{|c|}{ Frequency $[\mathrm{Hz}]$} & 125.0 & 160.0 & 200.0 & 250.0 & 315.0 & 400.0 & 500.0 \\
\hline \hline The bottom plate & 5.4 & 6.8 & 8.5 & 10.7 & 13.5 & 17.0 & 21.3 \\
\hline The left web plate & $\backslash$ & $\backslash$ & $\backslash$ & 5.3 & 9.6 & 9.8 & 11.1 \\
\hline The right web plate & $\backslash$ & $\backslash$ & $\backslash$ & 5.6 & 9.7 & 9.7 & 11.2 \\
\hline
\end{tabular}




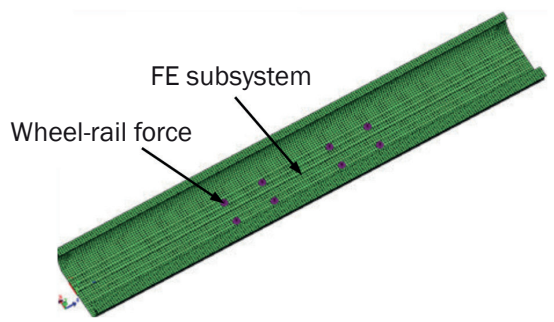

a) $1.25-125 \mathrm{~Hz} F E$ model

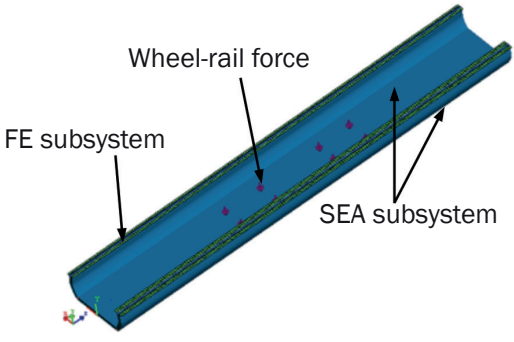

b) $125-250 \mathrm{~Hz}$ FE-SEA hybrid model

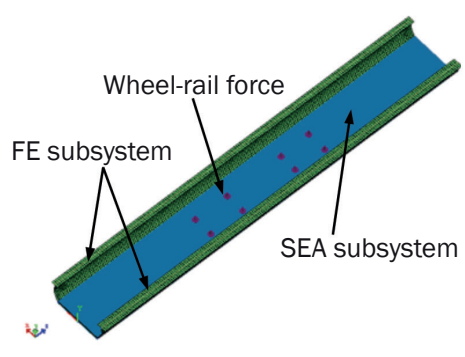

c) $250-500 \mathrm{~Hz}$ FE-SEA hybrid model

Figure 7 - U-beam model

\subsection{Validation}

The U-beam model and the vehicle loading parameters are nearly the same as those used in [9]. The reference acceleration is $\mathrm{Re}=1 \times 10^{6} \mathrm{~m} / \mathrm{s}^{2}$. The simulation value based on the proposed model for the total vertical acceleration level of the mid bottom plate is 114.9 $\mathrm{dB}$, which is almost the same as the measured value $114.8 \mathrm{~dB}$ when the train is running on a $30 \mathrm{~m} \mathrm{sin}$ gle-line simply supported U-beam at the speed of 70 $\mathrm{km} / \mathrm{h}$ [9]. Because the proposed model only considers a single-hole U-beam and neglects the influence of the parameters relating to the backing plates and piers, adopting a theoretical instead of practical wavelength range of the track irregularity, the simulation value of the sound pressure level at the point $2 \mathrm{~m}$ under the bridge is slightly lower than the measured value in [9]. However, the frequency corresponding to the peak value (maximum-amplitude frequency) and the trend are generally consistent, as shown in Figure 8 . The overall sound pressure level at the far-field point is $70.5 \mathrm{~dB}$. This value is close to the simulation value of the linear

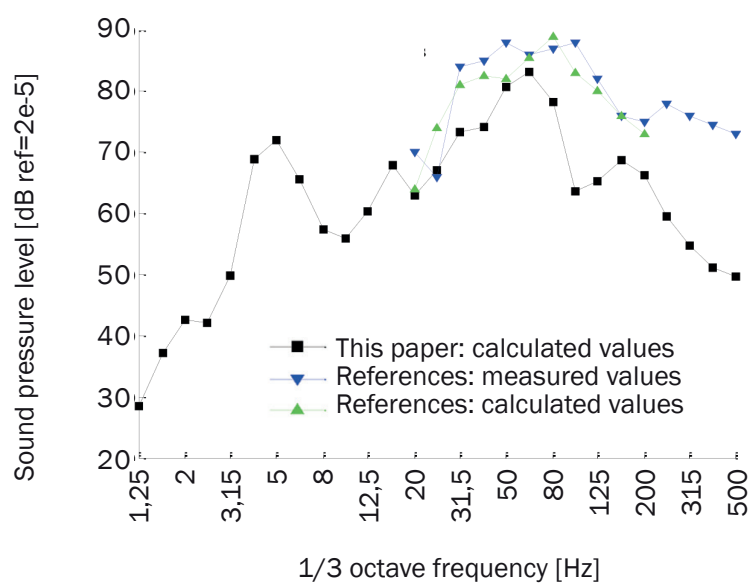

Figure 8 - Comparison of sound pressure levels between the calculated results in this paper and the results in [9]

sound pressure level $70.6 \mathrm{~dB}$ at the $3^{\text {rd }}$ far-field point of the $2^{\text {nd }}$ model in [7], which proves the reliability of the proposed model.

Table 3 compares the computation cost for each method. Compared with the methods in [10], the proposed model improves the computation efficiency while keeping the computation accuracy.

Table 3 - Comparison between calculation methods

\begin{tabular}{||l|c|c|c|c||}
\hline \multicolumn{1}{|c|}{ Method } & Model & $\begin{array}{c}\text { Computer } \\
\text { requirements }\end{array}$ & $\begin{array}{c}\text { Calculation time } \\
\text { [hour] }\end{array}$ & $\begin{array}{c}\text { Result file size } \\
\text { [gigabyte] }\end{array}$ \\
\hline \hline Proposed method & 3D $(1.25-500 \mathrm{~Hz})$ & low & $<0.5$ & $<1$ \\
\hline 2.5D IFE & 2D $(20-200 \mathrm{~Hz})$ & low & $2-3$ & 1 \\
\hline 3D BEM & 3D $(20-200 \mathrm{~Hz})$ & high & $22-24$ & 20 \\
\hline
\end{tabular}




\section{VIBRATION RESPONSES}

Using the U-beam model, the vertical acceleration level at the midpoint of the U-beam is obtained as shown in Figure 9. It can be seen from Figure 9 that the acceleration level of the U-beam (global vibration) has its peak at about $4 \mathrm{~Hz}$ to $5 \mathrm{~Hz}$ in the frequency range below $6.3 \mathrm{~Hz}$. The frequency responses of the left and right web plates are almost the same in the frequency range below $20 \mathrm{~Hz}$. In addition, the acceleration level of each plate (local vibration) has peaks at $40 \mathrm{~Hz}, 63$ $\mathrm{Hz}$, and $160 \mathrm{~Hz}$, respectively. The maximum-amplitude frequency of the acceleration levels for all plates (the bottom plate, the web plates, and the wing plates) are all at $63 \mathrm{~Hz}$. The maximum acceleration levels of the left and right wing plates, the left and right web plates, and the bottom plates are $92.6 \mathrm{~dB}, 92.2 \mathrm{~dB}, 90.1 \mathrm{~dB}$, $86.9 \mathrm{~dB}$, and $91.4 \mathrm{~dB}$, respectively. Under $63 \mathrm{~Hz}$, the wing plates have the maximum acceleration level, whereas above $63 \mathrm{~Hz}$, the bottom plate has the maximum. The dominant frequency band of the acceleration levels is mainly between $40 \mathrm{~Hz}$ and $80 \mathrm{~Hz}$. Thus, this frequency band should be the focus for vibration reduction.

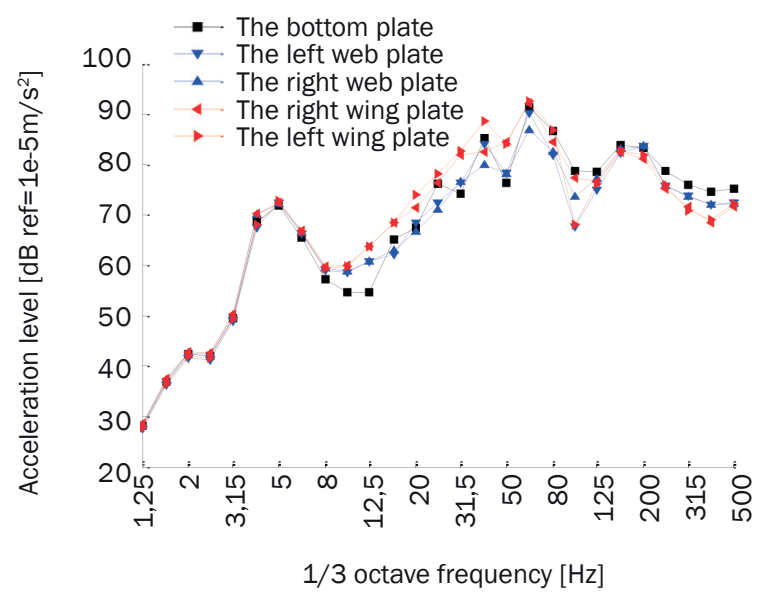

Figure 9 - 1/3 octave frequency spectrum of the vertical acceleration level of each plate in the middle section of the U-beam

\section{STRUCTURAL NOISE}

\subsection{Near-field sound pressure level}

To analyze the acoustic radiation of the structure, the sound pressure level of each plate in the near-field zone ( $0.3 \mathrm{~m}$ away the central surface of each plate) is calculated by Equations 6 and 7. The results are shown in Figure 10.

It can be seen from Figure 10 that the frequency corresponding to the peak values of the sound pressure levels of all plates in the near-field zone are at $63 \mathrm{~Hz}$, which is consistent with the conclusion in [7]

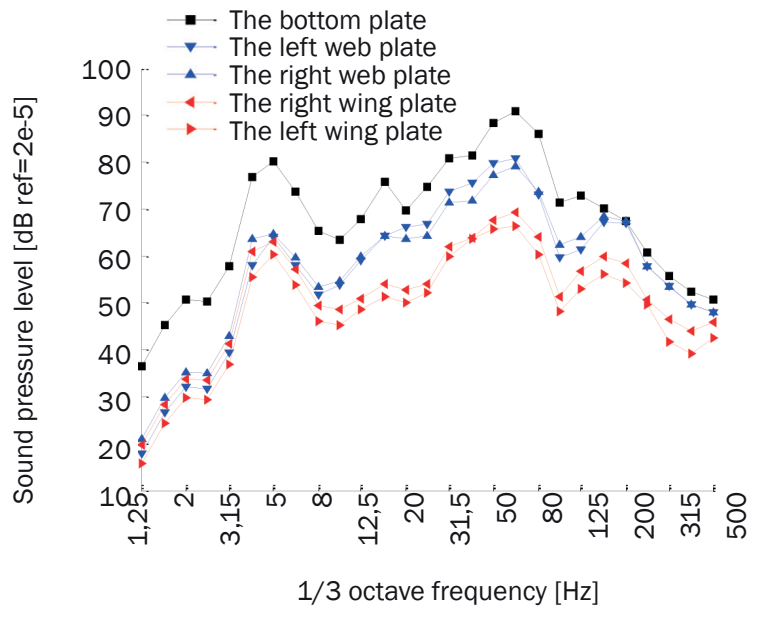

Figure 10 - Sound pressure level of each plate in the nearfield zone (0.3 $\mathrm{m}$ from the center surface)

that the frequency corresponding to the peak value of linear sound pressure level of the U-beam structural noise is between $40 \mathrm{~Hz}$ and $80 \mathrm{~Hz}$. Similar to the acceleration level, the dominant frequency band of the structural noise in the near-field zone is mainly between $40 \mathrm{~Hz}$ and $80 \mathrm{~Hz}$. In the near-field zone, the sound pressure level of the bottom plate is the highest among all plates, followed by the web plates. The wing plates have the minimum sound pressure level. As the frequency increases, the difference in the sound pressure level between the bottom plate and the web plates is gradually decreasing.

The maximum amplitudes of the sound pressure levels of the left and right web plates are $80.9 \mathrm{~dB}$ and $79.2 \mathrm{~dB}$, respectively. The sound pressure levels of the left web plate and the right web plate are close at each frequency. However, in the $20 \mathrm{~Hz}$ to $63 \mathrm{~Hz}$ range and the $250 \mathrm{~Hz}$ to $500 \mathrm{~Hz}$ range, the sound pressure level of the left web plate is higher, whereas that of the right web plate is higher in the other bands. The maximum amplitudes of the sound pressure levels of the left and right wing plates are $66.5 \mathrm{~dB}$ and $69.3 \mathrm{~dB}$, respectively. In the whole frequency range considered, the sound pressure level of the right wing plate is slightly higher than that of the left wing plate. This is because the right wing plate is wider and thinner than the left wing plate. Although the wing plates have higher acceleration levels, they have lower structural noise due to their smaller sizes.

\subsection{Sound pressure contribution}

To analyze the contribution to the sound pressure in the under-the-bridge zone and the far-field zone from each plate of the U-beam, so that effective noise reduction strategies can be established, two sound pressure prediction points were set. The point $\mathrm{P}$ (under-thebridge zone) was set $2.25 \mathrm{~m}$ vertically away from the mid-point of the span plate. The point M (far-field) was 
set $4.4 \mathrm{~m}$ vertically and $30 \mathrm{~m}$ horizontally away from the mid-point of the span plate, which is similar to the position of building windows at the ground floor level.

The sound pressure levels at point $\mathrm{P}$ due to all plates (beam) and due to each plate can be calculated by Equation 7. The results are shown in Figure 11. The sound pressure levels at point $\mathrm{M}$ due to all plates and due to each plate can be calculated by Equation 8 . The results are shown in Figure 12. Consistent with the acceleration levels, as well as the sound pressure level in the nearfield zone, the dominant frequencies of the structural noise at the far-field point and the under-the-bridge point

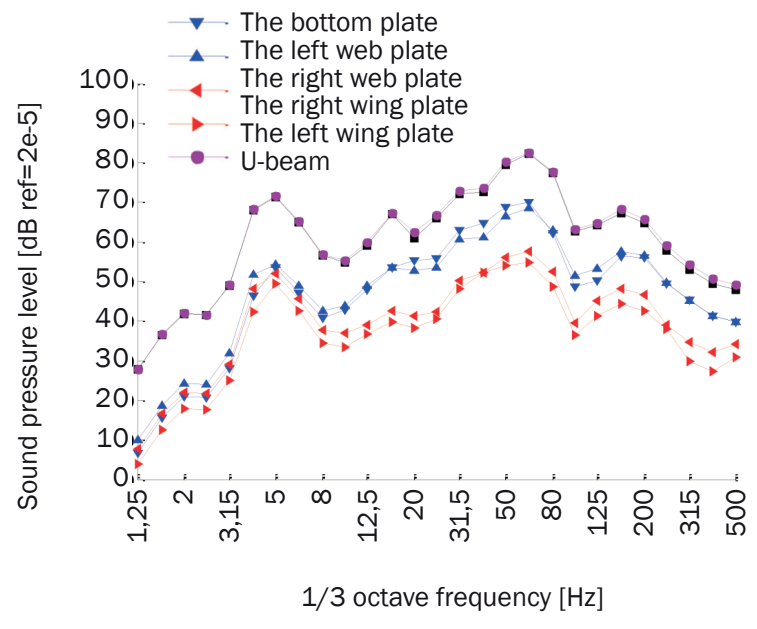

Figure 11 - Sound pressure level due to each plate and the $U$-beam at point $P$

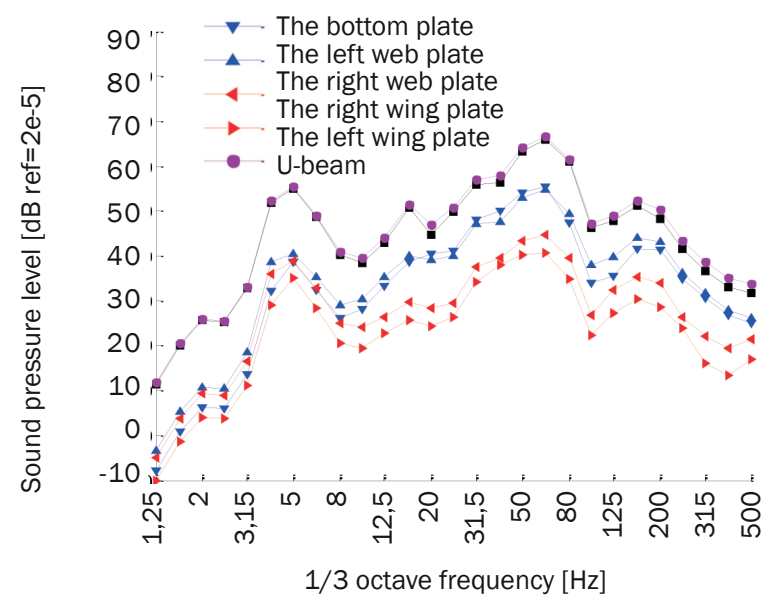

Figure 12 - Sound pressure level due to each plate and the $U$-beam at point $M$ are mainly concentrated within the $40 \mathrm{~Hz}$ to $80 \mathrm{~Hz}$ frequency range. Therefore, this frequency band should also be the focus for noise reduction.

It can also be seen from Figures 11 and 12 that the trends of the sound pressure levels at point $\mathrm{P}$ and $\mathrm{M}$ due to all plates are almost identical to those due to only the bottom plate. In fact, the sound pressure levels of the bottom plate play a major role at each frequency band and are much higher than the sum of the sound pressure levels of the remaining plates, which indicates that the main contribution source to the U-beam structural noise comes from the vibration of the bottom plate.

Taking the point $\mathrm{M}$ as an example, at the main excitation frequency $(63 \mathrm{~Hz})$, the actual percentage contribution to the total sound pressure of the U-beam at point $\mathrm{M}$ from the individual sound pressure of each plate at that point can be calculated by Equation 9. The results are shown in Table 4 . The contribution of the bottom plate reaches $85 \%$. The web plates have insignificant influence on the sound pressure level at point $\mathrm{M}$, whereas the wing plates have negligible influence. The contributions to the total sound pressure level at point $\mathrm{M}$ from the web plates and the wing plates in the low frequency range are negative; the contribution from the left web plate is larger than that from the right web plate.

\subsection{Vibration power level and energy level analysis}

The input vibration power level, output vibration power level as well as the vibration power level loss (difference between the input and output vibration power level) of the U-beam in the frequency domain are shown in Figure 13. It can be seen from Figure 13 that the vibration power level loss of the beam is about $15.4 \mathrm{~dB}$ to $34.5 \mathrm{~dB}$.

The vibration power level loss decreases with the increase of frequency in the frequency range below 63 $\mathrm{Hz}$ and gradually increases with the increase of frequency within the range of $63 \mathrm{~Hz}$ to $500 \mathrm{~Hz}$, meaning that the vibration power level loss reaches minimum at the main excitation frequency of the wheel-rail force (63 Hz).

The vibration energy level of the U-beam is shown in Figure 14. It can be seen from Figure 14 that the variations of the vibration energy level at each plate of the U-beam are nearly consistent with those of the sound pressure level of each plate (near-field), that is, the

Table 4 - Percentage contribution of each plate at $63 \mathrm{~Hz}$ (Point M)

\begin{tabular}{|c|c|c|c|c|c|c||}
\hline & Overall & $\begin{array}{c}\text { The bottom } \\
\text { plate }\end{array}$ & $\begin{array}{c}\text { The right } \\
\text { web plate }\end{array}$ & $\begin{array}{c}\text { The right wing } \\
\text { plate }\end{array}$ & $\begin{array}{c}\text { The left } \\
\text { wing plate }\end{array}$ & $\begin{array}{c}\text { The left } \\
\text { web plate }\end{array}$ \\
\hline \hline $\begin{array}{c}\text { Point M } \\
{[\mathrm{dB}]}\end{array}$ & \multirow{2}{*}{66.7} & 65.9 & 54.9 & 44.8 & 40.7 & 55.4 \\
\cline { 3 - 7 } & $85 \%$ & $6.6 \%$ & $0.7 \%$ & $0.3 \%$ & $7.4 \%$ \\
\hline
\end{tabular}




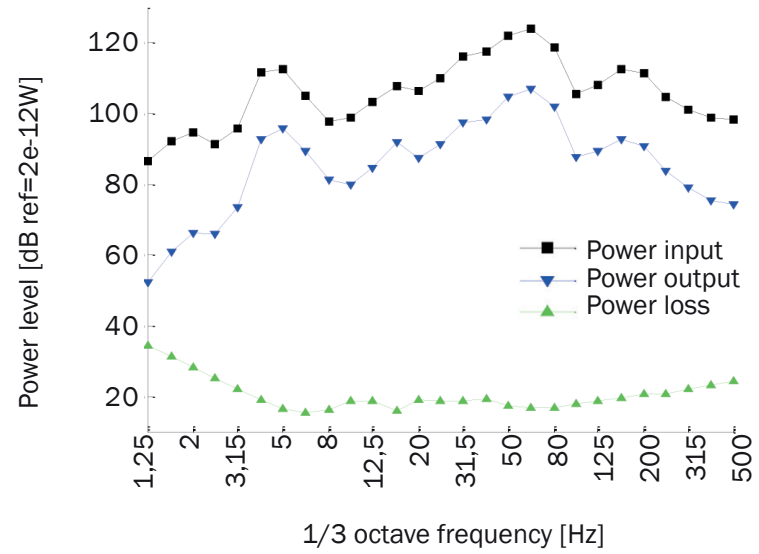

Figure 13 - Vibration power level loss of the U-beam

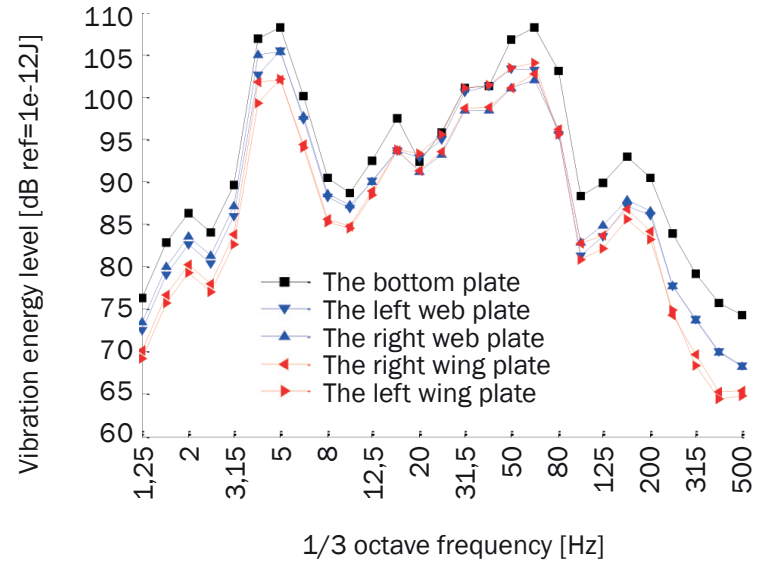

Figure 14 - Vibration energy level of the U-beam

vibration level and sound level of the bottom plate are the highest, seconded by those of the web plates, and then the wing plates.

The modal analysis of the U-beam is also performed as shown in Figure 15. The color (from blue to red) represents the severity of the vibration (from low to high). Based on the mode shapes provided for several orders, the maximum-amplitude frequency for the global vibration is within $4 \mathrm{~Hz}$ to $5 \mathrm{~Hz}$, and within $50 \mathrm{~Hz}$ to $63 \mathrm{~Hz}$ for the local vibration. Besides, the maximum amplitudes for global vibration and local vibration are close. By comparing the 30-order and 81-order mode shapes, the local vibration of the bottom plate and the web plates at $160 \mathrm{~Hz}$ is obviously lower than that at $63 \mathrm{~Hz}$, which is consistent with the results shown in Figure 13.

\section{CONCLUSIONS}

In this paper, the FE-SEA hybrid method was used to establish the local vibration simulation model of a U-beam structure of a rail transit system under the action of vertical wheel-rail interaction forces. The local vibration and the structural noise of the U-beam are quantitatively analyzed from $0 \mathrm{~Hz}$ to $500 \mathrm{~Hz}$. According to the modal density of the U-beam, the system is divided into FE and SEA sub-systems. This modeling strategy avoids the significant amount of calculation related to the FE model in the high frequency range and the poor performance related to the SEA model in the low frequency range. The contradiction between the computational efficiency and accuracy is solved, which extends the frequency range when analyzing the U-beam local vibration and improves the prediction accuracy while keeping the calculation efficiency.

The local vibration response and structural noise of the $30 \mathrm{~m}$ single-line simply supported U-beam reach maximum at the frequency which coincides with the main excitation frequency of the wheel-rail force (63 $\mathrm{Hz})$. The dominant frequency band $(40-80 \mathrm{~Hz})$ of the vibration acceleration level and the structural noise in the near-field zone, far-field zone, and under-thebridge zone of the U-beam is the same as that of the wheel-rail interaction force. Therefore, the frequency

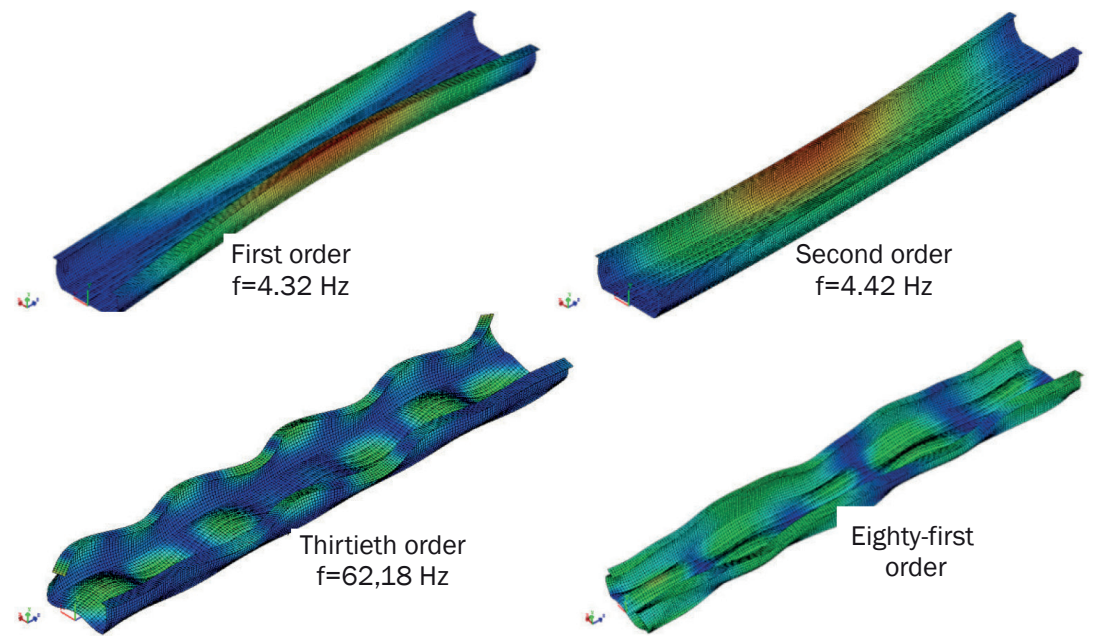

Figure 15 - U-beam vibration modes 
band containing the excitation frequencies should be the target when implementing strategies to reduce the vibration and structural noise of the U-beam.

The sound pressure level and the vibration acceleration level of the bottom plate are the highest among the five plates of the U-beam, seconded by those of the web plates, and then those of the wing plates. The bottom plate contributes the most to the sound pressure level at all prediction points. Therefore, the bottom plate should be the focus for noise and vibration reduction.

\section{ACKNOWLEDGEMENTS}

This research was partly supported by $\mathrm{Na}$ tional Natural Science Foundation (51468021, 51768022), Jiangxi Province Youth Key Foundation (20171ACB21037).

罗文俊, 博士 ${ }^{1}$

Email: Iwj06051979@163.com

程龙, 硕士 ${ }^{1}$

Email: 1580171291@qq.com

童立红, 博士 ${ }^{1}$

Email: Intong@ecjtu.edu.cn

余文念, 博士 ${ }^{2}$ (通讯作者)

Email: wennian.yu@queensu.ca

Chris K. Mechefske, 博士 ${ }^{2}$

Email: chris.mechefske@queensu.ca

1 中国江西省南昌市经济技术开发区双港东大街808号华 东交通大学 330013

2 Mclaughlin Hall, 130 Stuart Street, Queen's University, Kingston, Ontario, Canada, K7L 3N6

\section{基于FE-SEA混合法U型梁结构噪声预测分析}

摘要:

面对日益严重的城市轨道交通结构噪声问题，为精确 快速预测分析其在中低频的频谱特性。本文基于有限元统 计能量 (FE-SEA) 混合法分频段建立了的U型梁振动预测 模型，分析了垂向轮轨力作用下 $1.25 \mathrm{~Hz} \sim 500 \mathrm{~Hz}$ 频段内U 型梁振动及结构噪声的频域及空间特性。与文献中的其他 方法相比，本文采用FE-SEA混合法在保证较好精度的同时 能够提高计算效率, 从而扩展了结构振动与噪声的研究频 率范围。U型梁主要的减振降噪频段应是作用在其上的轮 轨力的优势频段。同时, 结果表明, 底板的声压值贡献量 在各个场点均起主要控制作用, 因此其应作为主要减振降 噪对象。

关键词:

U 型梁; 局部振动; 结构噪声; 声贡献量; FE-SEA混合法

\section{REFERENCES}

[1] Ross Z, Kheirbek I, Clougherty JE, Ito K, Matte T, Markowitz S, Eisl H. Noise, air pollutants and traffic: continuous measurement and correlation at a high-traffic location in New York City. Environmental Research. 2011;111(8): 1054-1063.

[2] Schulte-Werning B, Beier M, Degen KG, Stiebel D.
Research on noise and vibration reduction at DB to improve the environmental friendliness of railway traffic. Journal of Sound and Vibration. 2006;293(3-5): 10581069.

[3] Alten K, Flesch R. Finite element simulation prior to reconstruction of a steel railway bridge to reduce structure-borne noise. Engineering Structures. 2012;35: 83-88.

[4] Thompson DJ. Railway noise and vibration: mechanisms, modeling and means of control. $1^{\text {th }}$ Edition. Oxford, UK: Elsevier; 2009.

[5] Bewes OG, Thompson DJ, Jones CJC, Wang A. Calculation of noise from railway bridges and viaducts: Experimental validation of a rapid calculation model. Journal of Sound and Vibration. 2006;293(3-5): 933-943.

[6] Li X, Zhang X, Li Y. [Application of boundary element method in study of noise from simply-supported box girder in high speed railway]. China Civil Engineering Journal. 2011;(S1): 95-101. Chinese

[7] Han J, Wu D, Li Q. [Influence of deck thickness and stiffeners on structure-borne noise of the trough beams]. Journal of Vibration Engineering. 2012;5: 589-594. Chinese

[8] Li K, Zhang N, Xia H, et al. [Structural noise analysis of $32 \mathrm{~m}$ simply supported groove beam bridge on high speed railway]. Chinese Railway Science. 2015;36(4): 52-59. Chinese

[9] Li Q, Wu D. [Numerical simulation and field tests of concrete bridge-borne low-frequency noises]. Journal of the China Railway Society. 2013;3: 89-94. Chinese

[10] Song X, Wu D, Li Q. [A 2.5-dimensional infinite element based method for the prediction of structure-borne low-frequency noise from concrete rail transit bridges]. Journal of Vibration Engineering, 2015;6: 929-936. Chinese

[11] Shorter P, Langley R. Vibro-acoustic analysis of complex systems. Journal of Noise and Vibration. 2005;288(3): 669-699.

[12] Langley R, Cordioli A. Hybrid deterministic-statistical analysis of vibro-acoustic systems with domain couplings on statistical components. Journal of Sound and Vibration. 2009;321(3-5): 893-912.

[13] Southwest Jiaotong University. [ICE Technical Task Book for German Federal Railways Intercity Express Train]. Chengdu, China: Southwest Jiaotong University Press; 1993. pp. 301-309. Chinese

[14] Wang F. [Vehicle system dynamics]. Beijing, China: Railway Publishing Press; 1994. pp. 19-23. Chinese

[15] Railway Engineering Research Institute. [Academy of Railway Science Research Series of China's Research Report on Uneven Power Spectrum of Trunk Tracks]. Beijing, China: Academy of Railway Sciences; 1999. pp. 1-10. Chinese

[16] Zhang X, Zhang J, Li X. [Hybrid FE-SEA model and test validation for box-girders radiated low-frequency noise]. Journal of Vibration Engineering. 2016;(2): 245. Chinese

[17] Lei X, Sheng X. [Railway traffic noise and vibration]. Beijing, China: Science Press; 2004. Chinese

[18] Li X, Zhang X, Liu Q, et al. [Study on the full band prediction of bridge structure noise in high speed railway (I): theoretical model]. Journal of China Railway Society. 2013;35(1): 101-107. Chinese 